INVITED REVIEW

\title{
Nature and nurture in hearing: Critical periods for therapy of deafness
}

\author{
Andrej Kral ${ }^{1,2, *}$ and Mika Sato ${ }^{1}$ \\ ${ }^{1}$ Institute of AudioNeuroTechnology and Dept. of Experimental Otology, ENT Clinics, \\ Hannover Medical University, Stadtfelddamm 34, D-30625 Hannover, Germany \\ ${ }^{2}$ School of Medicine and Health Sciences, Macquarie University, Sydney, Australia
}

\begin{abstract}
The present manuscript reviews the contribution of cochlear implants to the understanding of the impact of congenital deafness on brain development. The results show that many characteristics of the afferent auditory system, particularly the anatomical features, are genetically determined (are in origin "nature"), and that experience is used to maintain and improve them to allow discriminating auditory stimuli. Experience ("nurture") is additionally required to group the auditory features at the level of the auditory cortex into abstract "auditory objects." This requires interaction between bottomup and top-down streams of information processing, since features define objects and context (i.e. active objects) defines which features may carry relevant information in the given condition. The interaction of feature- and object-level-representation is allowed by columnar microcircuits. The integration of bottom-up and top-down streams of information also controls adult learning. Since congenital deafness interferes with the relevant microcircuitry of the cortical column, congenital deafness, if persisting beyond certain age, also leads to failure of key high-level auditory processes including the switch between juvenile and adult learning and therefore closes the sensitive periods for its therapy.
\end{abstract}

Keywords: Development, Deafness, Cochlear implant, Hearing loss, Auditory cortex

PACS number: 43.64.Me, 43.64.Qh [doi:10.1250/ast.41.54]

\section{INTRODUCTION}

Sensory deprivation has been in focus of neuroscience since the time when the groundbreaking studies of Hubel and Wiesel provided evidence that the visual brain is developmentally plastic and that sensitive periods exist [1-3]. The most popular model has been monocular deprivation that, if initiated in early development, resulted in near complete loss of functional influence of the deprived ear on cortical neurons, i.e. lead to monocular blindness even if vision was restored late in development. While this concept has been supported by many recent studies [4-6], some aspects have been modified over the years. For example, while initially it has been assumed that initial formation of ocular dominance columns and their later modification by e.g. monocular deprivation, are both resulting from the same mechanisms, more recent studies revealed that this is not the case [7].

The concepts developed in the visual system have been assumed to hold also for other sensory systems. Nonetheless, the investigations in the visual system have been performed on cortical circuits specialized for visual processing, with complex patterns of interconnections

*e-mail: kral.andrej@mh-hannover.de resulting in orientation, color and ocular dominance columns assembled into so-called hypercolumns. This architecture is special in the visual system and results in the unique appearance of the primary visual cortex that differs from other sensory regions even when inspected under the microscope.

Experiments like those performed on the visual system were difficult to replicate in the auditory system. Visual deprivation can be induced by eyelid suturing or dark rearing. In the auditory system such modifications do not work: there is no equivalent to dark rearing, since in the auditory system the subject itself can produce sounds by interaction with the environment. Also closure of the ear canal does not result in hearing loss of more than $30 \mathrm{~dB}$, which would be considered clinically as only as a "mild hearing loss" [8]. Furthermore, "somatosounds" produced by the animal itself (vocalizations, swallowing, sneezing, chewing, breathing, etc.), are not attenuated at all (may even by slightly amplified). In consequence, only destruction of the ear leads to total sound deprivation; however, this intervention is irreversible and precludes testing functional properties.

Therefore it took science more than three decades to reverse such dramatic hearing loss using cochlear implants $[8,9]$. These devices stimulate the auditory nerve electri- 
cally and bypass the non-functional inner ear. Therefore, in combination with natural models of congenital deafness, like the deaf white cat [10-12] or pharmacologically neonatally deafened animals $[13,14]$, deprivation and its functional restoration has become available in the auditory system. These studies could consequently be compared to outcomes in implanted humans, making the auditory system a model system to study deprivation. Last but not least, also consequences for development of language could be tested using implants.

\section{LEARNING, DEAFNESS AND CRITICAL PERIODS}

Learning in normal hearing animals developmentally undergoes a transition from (juvenile) learning based on passive exposure to (adult) learning based on internal control. This has been documented in all sensory systems, in the auditory system on several experimental models [15-19]. Therefore, juvenile brain plasticity is high and learning facilitated in childhood, particularly so-called statistical learning based on frequency of occurrence of sensory stimuli. Nonetheless, many of the functional properties in the afferent auditory pathway are inborn, resulting in inborn feature discrimination ability [20-22]. The brain of the young child is therefore designed to discriminate (differentiate) auditory stimuli. With experience, based on the high brain plasticity, it gains the ability to relate the features to each other and to group the features into auditory objects (entities that can be differentiated from the background, [23]). We learn to use such internal object-level representations to identify certain reoccurring biologically-relevant stimuli despite some inherent feature variability. A rose becomes a rose, despite the many different appearances, colors, sizes, despite the fact that each rose is in detail different from any other one. We gain the ability to generalize and abstract. This is also the basis for learning language, and among the first signs of this process is the loss of the ability to discriminate sounds that are not discriminated in mother tongue [24]. The loss in sensitivity for foreign phonemes is likely a by-product of the generalizations required to cope with the inherent variability of sounds of the mother tongue.

These concepts have been supported by studies on deaf animals tested with cochlear implants, demonstrating rudimentary feature representation, albeit with some degradation of this ability (review in [25]). Interestingly, some of the deficits observed here could be counterbalanced by early cochlear implantation and chronic stimulation using a portable sound processor [26-30]. Also specific adaptations to electrical stimulation were observed $[13,26,31,32]$. These and other studies provided the evidence base for the present clinical use of the cochlear implants in pediatric hearing loss [8].
Critical periods for cochlear-implants related hearing restoration have been observed: only early implantation, within the first months of life in the cat, could induce extensive plasticity and maturation in the auditory system [27], similar to what was observed in the visual system. This cochlear-implant induced maturation, when initiated early in life, likely rests on the higher (juvenile) synaptic plasticity of the brain based on a juvenile composition of the synaptic apparatus on excitatory and inhibitory synapses and cell membrane properties [18,33-35].

However, also dissimilarities were observed to the visual system: In single-sided deafness the deaf ear was underrepresented in the cortex bilaterally if the deafness set in within an early sensitive period [36-38], however, in no case the representation of the deprived sensory organ was eliminated in the auditory cortex. In the visual system, on the other hand, the eye occluded lost the ability to drive cortical neurons, leading to blindness on that eye (discussion in $[37,39])$. Such better preservation of the deprived ear was found despite of the substantially longer and more severe auditory deprivation than the deprivation tested in the visual system [37,39]. The difference is most likely the consequence of the different architecture of these two sensory systems. In the visual system the binocular convergence appears first in the primary visual cortex, whereas in the auditory system it takes place already in the brainstem and the cortex only inherits the binaural properties [39]. The site of convergence and the different plasticity potential of these structures explain the different susceptibility of the respective systems to monaural and monocular deprivation.

Additional observations allowed eventually explaining why in profoundly deaf children a critical period for therapy is observed [40-42]. Congenital deprivation resulted in an extensive deficit in the processing of cortical columns, with desynchronization of activity between layers and loss of activity in deep layers [43], reversible by early cochlear implant stimulation [29]. In addition, a morphological correlate in dystrophic changes of layers IV, V and VI was recently observed in both primary and two secondary auditory areas [44]. Since the deep layers V and VI are the major source of long-range top-down information, and together with upper layers also a recipient of top-down influences, these observations suggested that the cortical column loses the ability to integrate the bottom-up and top-down stream of information in congenital deafness $[22,45]$. Recently, evidence supporting this concept was obtained using analysis of oscillatory cortical responses. These can be differentiated into evoked and induced [46]. Evoked responses are strongly determined by the sensory stimulus and thus are tightly phase-locked to the stimulus. Therefore, they appear at the same phase and timing with each repetition of the stimulus. Induced 
responses, on the other hand, are generated by the stimulus, but differ in phase and timing between trials; they typically appear $100 \mathrm{~ms}$ or more after the stimulus onset. They are the consequence of the interaction between sensory (thalamic) input and other active corticocortical (topdown) inputs. A dissociation of the effect of congenital deafness on evoked and induced responses was noted, with much more extensive effects on the induced responses in both primary and secondary auditory areas [47]. It was consequently concluded that the ability to integrate the sensory input into cortical processing is substantially compromised in congenital deafness [47]. This is of much more than theoretical importance: such interaction is essential for learning that in the adult subjects is initiated by a violation of expectation - from so-called prediction error [48-50].

In consequence, the congenitally deaf auditory system at the end of the developmental period reaches a state that is somewhere in between the juvenile, highly plastic state capable of learning through passive stimulus exposure and the adult, less plastic but characterized by learning controlled by the subject and the active internal model. Neither mechanisms work, the brain is in condition where adaptive plasticity is no longer possible and critical periods for therapy close [23].

Finally, an additional well-known process may contribute to closure of critical periods: a take-over of the deprived auditory system by another modality, e.g. the visual modality. This process has been a popular model for plasticity in all sensory systems [51-53]. However, the correlate of cross-modal plasticity has not been observed in all tested functions, and not all visual abilities were improved in congenitally deaf [52], indicating some limits in cross-modal plasticity. When this has been tested on congenitally deaf cats, out of seven visual functions only two were supranormal compared to hearing cats, namely visual localization to periphery and visual movement detection [54]. This matched the supranormal functions described in deaf humans $[51,55,56]$. The supranormal functions could be assigned to two secondary areas in the cat [54]. Consequently, the question was asked whether these two areas remain responsive to auditory stimulation or whether responsiveness is substantially reduced or eliminated in these cross-modal fields.

First the anatomical connections were inspected. However, these fields remained predominantly connected to the auditory structures and only few ectopic projections to the visual and somatosensory systems were found $[57,58]$. This indicated that the anatomical connectivity (that forms well before hearing onset) is surprisingly robust to deprivation effects. When recordings were performed in both of these fields, responsiveness to auditory stimulation was confirmed [47,59]. In direct comparison, increase of visual responsiveness was noted, but this did not substantially reduce auditory responsiveness [59]. In consequence, these data indicate that the negative (adverse) effect of cross-modal reorganization on auditory function is smaller than previously assumed. While these studies do not support some of the hypotheses of the crucial role of crossmodal reorganization in closing critical periods, they opened the door for the potential of multimodal training therapies in pediatric hearing loss.

\section{CONCLUSIONS}

Several mechanisms in combination appear essential in delineating the critical periods for therapy of deafness (for review, see [22,23]):

- Synaptic plasticity that decreases with increasing age during the juvenile period. It decreases (but does not eliminate) the potential for reorganization of the brain by passive sound exposure, thus reduces statistical learning ability.

- Feature representation in the central auditory system requires experience for maintenance and improvement; in absence of experience, feature representation is degraded. This compromises the starting point for learning.

- Cortical synaptic development that depends extensively on hearing experience. In congenital deafness, cortical microcircuits designed to compare bottom-up and top-down streams of information are compromised, resulting in lack of prediction-error-based control of learning that is characteristic for adult-type of auditory plasticity.

- Recruitment of the auditory resources for other (e.g. visual) tasks may contribute to closure of critical periods, but this influence is weaker than the other three factors mentioned above.

\section{ACKNOWLEDGEMENTS}

Supported by Deutsche Forschungsgemeinschaft (Exc 1077) and National Science Foundation (USA).

\section{REFERENCES}

[1] T. N. Wiesel and D. H. Hubel, "Comparison of the effects of unilateral and bilateral eye closure on cortical unit responses in kittens," J. Neurophysiol., 28, 1029-1040 (1965).

[2] D. H. Hubel and T. N. Wiesel, "Binocular interaction in striate cortex of kittens reared with artificial squint," J. Neurophysiol., 28, 1041-1059 (1965).

[3] D. H. Hubel and T. N. Wiesel, "The period of susceptibility to the physiological effects of unilateral eye closure in kittens," J. Physiol., 206, 419-436 (1970).

[4] N. B. Sawtell, M. Y. Frenkel, B. D. Philpot, K. Nakazawa, S. Tonegawa and M. F. Bear, "NMDA receptor-dependent ocular dominance plasticity in adult visual cortex," Neuron, 38, 977985 (2003).

[5] M. Sato and M. P. Stryker, "Distinctive features of adult ocular dominance plasticity,” J. Neurosci., 28, 10278-10286 (2008). 
[6] M. Sato and M. P. Stryker, "Genomic imprinting of experience-dependent cortical plasticity by the ubiquitin ligase gene Ube3a," Proc. Natl. Acad. Sci. USA, 107, 5611-5616 (2010).

[7] J. C. Crowley and L. C. Katz, "Early development of ocular dominance columns," Science, 290, 1321-1324 (2000).

[8] A. Kral and G. M. O'Donoghue, "Profound deafness in childhood," N. Engl. J. Med., 363, 1438-1450 (2010).

[9] B. S. Wilson and M. F. Dorman, "Cochlear implants: A remarkable past and a brilliant future," Hear. Res., 242, 3-21 (2008).

[10] I. W. S. Mair, "Hereditary deafness in the white cat," Acta Otolaryngol.(Stockh.), 314(Suppl.), 1-53 (1973).

[11] S. Heid, R. Hartmann and R. Klinke, "A model for prelingual deafness, the congenitally deaf white cat: Population statistics and degenerative changes," Hear. Res., 115, 101-112 (1998).

[12] A. Kral and S. G. Lomber, "Deaf white cats," Curr. Biol., 25, R351-R353 (2015).

[13] R. L. Snyder, S. J. Rebscher, K. L. Cao, P. A. Leake and K. Kelly, "Chronic intracochlear electrical stimulation in the neonatally deafened cat. I: Expansion of central representation," Hear. Res., 50, 7-33 (1990).

[14] J. I. Matsushima, R. K. Shepherd, H. L. Seldon, S. A. Xu and G. M. Clark, "Electrical stimulation of the auditory nerve in deaf kittens: Effects on cochlear nucleus morphology," Hear. Res., 56, 133-142 (1991).

[15] S. G. Stanton and R. V. Harrison, "Abnormal cochleotopic organization in the auditory cortex of cats reared in a frequency augmented environment," Aud. Neurosci., 2, 97-107 (1996).

[16] L. I. Zhang, S. Bao and M. M. Merzenich, "Persistent and specific influences of early acoustic environments on primary auditory cortex," Nat. Neurosci., 4, 1123-1130 (2001).

[17] T. R. Barkat, D. B. Polley and T. K. Hensch, "A critical period for auditory thalamocortical connectivity," Nat. Neurosci., 14, 1189-1194 (2011).

[18] J. A. Blundon and S. S. Zakharenko, "Presynaptic gating of postsynaptic synaptic plasticity: A plasticity filter in the adult auditory cortex," Neuroscientist, 19, 465-478 (2013).

[19] J. A. Blundon, N. C. Roy, B. J. W. Teubner, J. Yu, T. Y. Eom, K. J. Sample, et al., "Restoring auditory cortex plasticity in adult mice by restricting thalamic adenosine signaling," Science, 356, 1352-1356 (2017).

[20] R. N. Aslin and D. B. Pisoni, "Some developmental processes in speech perception," in Child Phonology: Perception, G. H. Yeni-Komshian, J. H. Kavanagh and C. A. Ferguson, Eds. (Academic Press, New York, 1980), pp. 67-96.

[21] D. Maurer and J. F. Werker, "Perceptual narrowing during infancy: A comparison of language and faces," Dev. Psychobiol., 56, 154-178 (2014).

[22] A. Kral, P. A. Yusuf and R. Land, "Higher-order auditory areas in congenital deafness: Top-down interactions and corticocortical decoupling," Hear. Res., 343, 50-63 (2017).

[23] A. Kral, "Auditory critical periods: A review from system's perspective," Neuroscience, 247, 117-133 (2013).

[24] J. F. Werker and R. C. Tees, "The organization and reorganization of human speech perception," Annu. Rev. Neurosci., 15, 377-402 (1992).

[25] A. Kral and A. Sharma, "Developmental neuroplasticity after cochlear implantation," Trends Neurosci., 35, 111-122 (2012).

[26] R. Klinke, A. Kral, S. Heid, J. Tillein and R. Hartmann, "Recruitment of the auditory cortex in congenitally deaf cats by long-term cochlear electrostimulation," Science, 285, 17291733 (1999).

[27] A. Kral, R. Hartmann, J. Tillein, S. Heid and R. Klinke, "Hearing after congenital deafness: Central auditory plasticity and sensory deprivation," Cereb. Cortex, 12, 797-807 (2002).

[28] D. K. Ryugo, E. A. Kretzmer and J. K. Niparko, "Restoration of auditory nerve synapses in cats by cochlear implants," Science, 310, 1490-1492 (2005).

[29] A. Kral, J. Tillein, S. Heid, R. Klinke and R. Hartmann, "Cochlear implants: Cortical plasticity in congenital deprivation," Prog. Brain Res., 157, 283-313 (2006).

[30] J. B. Fallon, D. R. Irvine and R. K. Shepherd, "Cochlear implant use following neonatal deafness influences the cochleotopic organization of the primary auditory cortex in cats," J. Comp. Neurol., 512, 101-114 (2009).

[31] R. E. Beitel, M. Vollmer, R. L. Snyder, C. E. Schreiner and P. A. Leake, "Behavioral and neurophysiological thresholds for electrical cochlear stimulation in the deaf cat," Audiol. Neurootol., 5, 31-38 (2000).

[32] J. C. Middlebrooks, J. A. Bierer and R. L. Snyder, "Cochlear implants: The view from the brain," Curr. Opin. Neurobiol., 15, 488-493 (2005).

[33] V. B. Aramakis, C. Y. Hsieh, F. M. Leslie and R. Metherate, "A critical period for nicotine-induced disruption of synaptic development in rat auditory cortex," J. Neurosci., 20, 6106$6116(2000)$.

[34] T. M. Mowery, V. C. Kotak and D. H. Sanes, "Transient hearing loss within a critical period causes persistent changes to cellular properties in adult auditory cortex," Cereb. Cortex, 25, 2083-2094 (2015).

[35] R. C. Froemke, "Plasticity of cortical excitatory-inhibitory balance," Annu. Rev. Neurosci., 38, 195-219 (2015).

[36] A. Kral, P. Hubka, S. Heid and J. Tillein, "Single-sided deafness leads to unilateral aural preference within an early sensitive period," Brain, 136, 180-193 (2013).

[37] A. Kral, S. Heid, P. Hubka and J. Tillein, "Unilateral hearing during development: Hemispheric specificity in plastic reorganizations," Front. Syst. Neurosci., 7, 93 (2013).

[38] D. B. Polley, J. H. Thompson and W. Guo, "Brief hearing loss disrupts binaural integration during two early critical periods of auditory cortex development," Nat. Commun., 4, 2547 (2013).

[39] J. Tillein, P. Hubka and A. Kral, "Monaural congenital deafness affects aural dominance and degrades binaural processing," Cereb. Cortex, 26, 1762-1777 (2016).

[40] M. Manrique, F. J. Cervera-Paz, A. Huarte, N. Perez, M. Molina and R. García-Tapia, "Cerebral auditory plasticity and cochlear implants," Int. J. Pediatr. Otorhinolaryngol., 49, S193-S197 (1999).

[41] A. M. Robbins, D. B. Koch, M. J. Osberger, S. ZimmermanPhillips and L. Kishon-Rabin, "Effect of age at cochlear implantation on auditory skill development in infants and toddlers," Arch. Otolaryngol. Head Neck Surg., 130, 570-574 (2004).

[42] J. K. Niparko, E. A. Tobey, D. J. Thal, L. S. Eisenberg, N. Y. Wang, A. L. Quittner and N. E. Fink, "Spoken language development in children following cochlear implantation," J. Am. Med. Assoc., 303, 1498-1506 (2010).

[43] A. Kral, R. Hartmann, J. Tillein, S. Heid and R. Klinke, "Congenital auditory deprivation reduces synaptic activity within the auditory cortex in a layer-specific manner," Cereb. Cortex, 10, 714-726 (2000).

[44] C. Berger, D. Kühne, V. Scheper and A. Kral, "Congenital deafness affects deep layers in primary and secondary auditory cortex," J. Comp. Neurol., 525, 3110-3125 (2017).

[45] A. Kral and J. J. Eggermont, "What's to lose and what's to learn: Development under auditory deprivation, cochlear implants and limits of cortical plasticity," Brain Res. Rev., 
56, 259-269 (2007).

[46] M. Siegel, T. H. Donner and A. K. Engel, "Spectral fingerprints of large-scale neuronal interactions," Nat. Rev. Neurosci., 13, 121-134 (2012).

[47] P. A. Yusuf, P. Hubka, J. Tillein and A. Kral, "Induced cortical responses require developmental sensory experience," Brain, 140, 3153-3165 (2017).

[48] R. A. Rescorla and R. L. Solomon, "Two-process learning theory: Relationships between Pavlovian conditioning and instrumental learning," Psychol. Rev., 74, 151-182 (1967).

[49] R. A. Rescorla, "The psychology of learning: Conditioning and associative learning," Science, 223, 388-389 (1984).

[50] K. Friston, "The free-energy principle: A unified brain theory?" Nat. Rev. Neurosci., 11, 127-138 (2010).

[51] H. J. Neville, "Intermodal competition and compensation in development. Evidence from studies of the visual system in congenitally deaf adults," Ann. N. Y. Acad. Sci., 608, 71-87 (1990); discussion 87-91.

[52] D. Bavelier, M. W. Dye and P. C. Hauser, "Do deaf individuals see better?" Trends Cogn. Sci., 10, 512-518 (2006).

[53] L. B. Merabet and A. Pascual-Leone, "Neural reorganization following sensory loss: The opportunity of change," Nat. Rev.
Neurosci., 11, 44-52 (2010).

[54] S. G. Lomber, M. A. Meredith and A. Kral, "Cross-modal plasticity in specific auditory cortices underlies visual compensations in the deaf," Nat. Neurosci., 13, 1421-1427 (2010).

[55] E. M. Finney, I. Fine and K. R. Dobkins, "Visual stimuli activate auditory cortex in the deaf," Nat. Neurosci., 4, 11711173 (2001).

[56] E. M. Finney, B. A. Clementz, G. Hickok and K. R. Dobkins, "Visual stimuli activate auditory cortex in deaf subjects: Evidence from MEG,” Neuroreport, 14, 1425-1427 (2003).

[57] P. Barone, L. Lacassagne and A. Kral, "Reorganization of the connectivity of cortical field DZ in congenitally deaf cat," PLoS ONE, 8, e60093 (2013).

[58] B. E. Butler, N. Chabot, A. Kral and S. G. Lomber, "Origins of thalamic and cortical projections to the posterior auditory field in congenitally deaf cats," Hear. Res., 343, 118-127 (2017).

[59] R. Land, P. Baumhoff, J. Tillein, S. G. Lomber, P. Hubka and A. Kral, "Cross-modal plasticity in higher-order auditory cortex of congenitally deaf cats does not limit auditory responsiveness to cochlear implants," J. Neurosci., 36, 61756185 (2016). 